\title{
Workload during cardiopulmonary resuscitation
}

\author{
T. Küpper · J. Steffgen $\cdot$ A. Morrison $\cdot$ \\ J. Milledge $\cdot$ V. Schöffl
}

Received: 15 January 2013/ Accepted: 18 May 2014/Published online: 30 May 2014

(C) Springer-Verlag Berlin Heidelberg 2014

\begin{abstract}
Objectives Lay resuscitation is crucial for the survival of the patients with out-of-hospital cardiac arrest. Therefore, lay CPR should be a basic skill for everyone. With the growing proportion of retired people in the Western societies, CPR performed by people with preexisting diseases and at risk of cardiac events is expected to grow. There is little knowledge about the workload during CPR and the minimum workload capacity of the rescuer.

Methods Pulse frequency, oxygen uptake, and $\mathrm{CO}_{2}$ elimination were measured by telemetry, while CPR was
\end{abstract}

Trial registration No.: Ethical Commission of the University of Düsseldorf (No. 950).

\section{T. Küpper $(\bowtie)$}

Institute of Occupational and Social Medicine, RWTH Aachen Technical University, Pauwelstr. 30, 52057 Aachen, Germany e-mail: tkuepper@ukaachen.de

T. Küpper · A. Morrison · J. Milledge · V. Schöffl Medical Commission of the Union Internationale des Associations d'Alpinisme (UIAA), Bern, Switzerland

\section{J. Steffgen}

Department of Nephrology and Rheumatology, University of Göttingen, Göttingen, Germany

J. Milledge

Department of Physiology, University College of London

(UCL), London, UK

\section{Schöffl}

Department of Trauma and Orthopedic Surgery, Klinikum

Bamberg, Bamberg, Germany

V. Schöffl

Department of Trauma Surgery, Friedrich Alexander University Erlangen-Nuremberg, Erlangen, Germany performed using a manikin with digital equipment for the standardization of the procedure. The same parameters were measured during a standard exercise testing protocol (spiroergometry) on a bicycle to analyze the aerobic endurance range of the participants. Data from the resuscitation protocols were correlated with those from spiroergometry to establish a simple standard investigation procedure to check people at risk and to give minimum requirements to perform $\mathrm{CPR}$ in Watts $/ \mathrm{kg}$. The study consisted of two parts: $1 \quad(n=16)$ explored minimal workload cutoffs for the rescuer using the 1995 recommendations and $2(n=14)$ tested the latest 2010 guidelines to compare both recommendations.

Results When tested according to the 1995 guidelines, heart frequency of rescuers increased from $83.0 \mathrm{bpm}( \pm 11.3)$ at rest to $109.9 \mathrm{bpm}( \pm 12.6 ; P=0.0004)$. The newer 2010 guidelines increased the workload marginally more (n.s.).

Conclusion CPR can be performed by healthy people within the range of aerobic endurance. The minimal requirements for trainings are 1.6-1.8 W/kg body weight in standard cycling ergometry. People at risk should be trained very careful. Since there is no significant lower workload when following the 1995 recommendations, people at risk should be trained according to the latest recommendations. In the case of a real resuscitation, such trained individuals must additionally take into account any symptoms.

Keywords Resuscitation - Workload P Preexisting diseases $\cdot$ Coronary heart disease $\cdot$ Pulmonary diseases

\section{Introduction}

There is a general consensus that trained lay people performing cardiopulmonary resuscitation (CPR) can save 
life. Therefore, the training is recommended for the general population (e.g., Kida et al. 2004, Stiell et al. 2003), although there are some barriers (Lejeune and Delooz 1987) (Johnston et al. 2003). Such barriers and differences in the availability of CPR trainings cause significant regional differences: While lay rescuer CPR rates are low in Germany (10-15\%), they are much higher in Scandinavia (up to $50 \%$ ). One reason may be that CRP trainings are integral part of school teaching, already at elementary schools. Epidemiology of cardiac arrests is changing, probably based on the higher rate of patients treated for their coronary heart disease (less ventricular fibrillation). Nevertheless, with the increasing age of the population, there is an increased number of people at risk of cardiopulmonary diseases (CPD) (data for Germany in N.N. 2010). There is also an associated increased probability that these persons may join CPR training courses or that they may be required to perform a real resuscitation (Kelly 1986). The persons that could be trained in CPR safely is a relevant question.

The workload caused by CPR may pose an acute risk for a rescuer with a significant preexisting disease. But knowledge about this is limited. Shultz et al. found that a mean oxygen uptake of $18.2 \mathrm{ml} / \mathrm{kg} / \mathrm{min}$ and a ventilation of $35.5 \mathrm{l} / \mathrm{min}$ were required for CPR (Shultz et al. 1995). This is comparable with those of Nordic walking $(17 \mathrm{ml} / \mathrm{kg} /$ $\min )$ and a bit more than ordinary walking ( $14 \mathrm{ml} / \mathrm{kg} / \mathrm{min})$ (Church et al. 2002). A normal European population shows a maximal uptake of $29-34 \mathrm{ml} / \mathrm{kg} / \mathrm{min}$ (Vogt 2004) and if trained of those $38-42.2 \mathrm{ml} / \mathrm{kg} / \mathrm{min}$ (Klinger 2009). Normal daily work at home or in bureaus corresponds to 0.5-0.75 W/kg (Spitzer et al. 1982). Elite athletes show a multiple of that: $47-120 \mathrm{ml} / \mathrm{kg} / \mathrm{min}$ was reported (e.g., Neumann 1993; Castagna et al. 2009). The problem of these studies is that a comparison would be questionable, because the different unities given which would need detailed data about the respective collectives for a direct comparison.

CPR recommendations have changed several times. In 1995, the American Heart Association (AHA) recommendations stated a chest compression (CC) to artificial ventilation (AV) ratio 15:2 with a frequency of CC of $80 \mathrm{bpm}$ (Tucker et al. 1995). The 2000 recommendations, respectively, increased the frequency of CC to $15: 2$ and $100 \mathrm{bpm}$, which was increased again in 2005 to $30: 2$ with $100 \mathrm{bpm}$ in 2005 (N.N. 2000; Nolan et al. 2005; Neumar et al. 2010). The 1995 recommendations resulted in $\sim 60$ real CCs per minute, while those of 2000 in about $80 / \mathrm{min}$ and the actual ones close to $100 / \mathrm{min}$. It may be assumed that the workload of the rescuer increased with the increase in effective $\mathrm{CC}$ frequency.

Some old studies report cardiocirculatory data of the "rescuers" in CRP trainings, e.g., a heart rate of 115/min
(Lonergan et al. 1981). But the conditions of the experiments were insufficiently described, e.g., there is no information given about the frequency of $\mathrm{CC}$ or the depth of the compressions (Lonergan et al. 1981). Up to now, there are no data available which describe the workload during CPR in relation to a baseline workload measure to determine whether an individual is able to perform CPR safely or not. In exercise physiology, the aerobic endurance of a healthy person indicates whether he or she is able to perform a strengthenous work over a certain time. When a person may be limited by a cardiopulmonary disease, this limit is given by the onset of hypoxia-induced ECG changes or by any kind of cardiopulmonary symptoms ("ischemic threshold"). For safety reasons, these persons should not perform exercise above $80 \%$ of those for the ischemic threshold.

We therefore investigated the workload during CPR and cycling ergometry in healthy subjects to determine a standardized procedure by which physicians could advise patients with cardiopulmonary diseases as to whether they can train or perform CPR or not. For pragmatic reasons, the project consists of two parts: Because a more intense work should be more demanding, we assessed CPR workload for both the old 1995 guidelines and the new 2010 ones. The latter recommend a significant higher frequency of cardiocompressions, and therefore, the procedure should cause a higher workload. However, the 1995 recommendations were also effective, and for people with preexisting risks, it may be a safe option to perform CPR according to them with less workload compared with the 2010 recommendations. In consequence, the first part of the study assessed CPR workload according to the 1995 recommendations, which were in use until 2000; the second part used the latest 2010 CPR recommendations. The results of both parts were compared to give best possible recommendation.

\section{Material and Methods}

Part 1: A standard spiroergometry was performed on 16 healthy subjects at sea level (Hollmann and Hettinger 2000). The procedure is based on the linear correlation between HF and workload until the anaerobic threshold is reached (Hollmann and Hettinger 2000) (McGehee et al. 2005). Anthropometrical data (sex, age, and BMI) were also recorded.

"Healthy" was defined as adults having no CPD and with a normal blood count in order to comply with ethical permission for testing. Blood tests performed were hemoglobin, hematocrit, red cell and leukocyte count, and CO hemoglobin. In the absence of data available that could estimate the potential risk for elderly persons with 
preexisting cardiopulmonary diseases, ethical permission for these studies was restricted to testing young adults without any CPD and with normal blood cell count. We additionally excluded participants using any drugs, which might influence heart frequency or work performance, extensive amounts of coffee included.

For spiroergometry, an ergometer was used, which was independent from the revolutions per minute (Siemens/ Germany; ECG: 12 channels, Corinna, Marquette-Hellige Medical Systems) and combined with the telemetric spirometry system Cosmed K4 RQ (Cosmed Deutschland $\mathrm{GmbH}$, Hamburg). HF was measured using Polar pulse system (Polar Electro GmbH Deutschland, Büttelborn).

The Cosmed system was calibrated semi-automatically with $\mathrm{FiO}_{2} 20.95 \%, \mathrm{FiCO}_{2} 0.03 \%$, and sampling period of 5-s intervals. Data evaluation was performed by the system's software (Cosmed Win/EE). The data of the third minute of each load level of ergometry and during CPR were used for final evaluation to provide steady state conditions (Hollmann and Hettinger 2000). During steady state, arterialized capillary blood samples were taken to analyze blood gases (ABL 520, Radiometer Copenhagen/ Danmark) and lactate (Akkusport, Fa. Hestia/Boehringer Mannheim, Germany). Both blood gases and lactate were also taken at the end of the CPR protocols in both studies. Lactate (anaerobic) threshold was calculated as $4 \mathrm{mmol} / \mathrm{l}$ threshold ("Mader threshold") (Mader et al. 1976).

Part 1 was intended as pilot study to get data for the further discussion with the ethical committee and a first idea whether the workload may be within a range which may be realistic for rescuers with preexisting risk factors. Therefore, resuscitation was performed using single rescuer technique in full accordance with the 1995 guidelines (Tucker et al. 1995), which were expected to cause less workload. CPR was performed on a manikin (Skillmeter Resusci-Anne, Laerdal Ltd.), which provided an automated computerized and online documentation of the correct execution of the CPR. This includes sensors and an evaluation system, which analyses the correct depth of any single compression (which was set at $5 \mathrm{~cm}$ for our study) as well as the correct frequency. CPR was performed for a period of at least $3 \mathrm{~min}$ to provide steady state conditions which start after 2 min (Hollmann and Hettinger 2000). The frequency of the $\mathrm{CC}$ was controlled by a metronome. As the cycling workload to exhaustion protocol included a significant increase in lactate production, the CRP tests were performed the following day. All participants were medically lay persons who were trained in CPR.

Part 2: this part was intended to investigate whether the 2010 recommendations indeed cause a higher workload than the previous ones and to make a direct comparison of both. Since the collective of part 1 was not available anymore, a similar collective was chosen. The study design (spiroergometry to exhaustion the day before the CPR tests, collective data, used equipment, etc.) was identical to part 1. The differences to part 1 were as follows:

- Since study 1 had proven that CPR is an activity which is well within the range of pure aerobic endurance capacity for all participants and to include the situation with $\mathrm{AV}$, we focused on HF only in study 2 (Polar S810i).

- In part 1 , the mask of the Cosmed system prevented direct AV being performed on the manikin in part 1 . This was not considered a limitation as no further increase in the workload was anticipated as only the normal expiratory volume of the rescuer should be administered to the victim (Handley et al. 1997). However, this was checked more in detail in part 2, where we had four different settings, each of them for 3 min with a break of at least $20 \mathrm{~min}$ in between. Before the beginning of the next test, the probands were checked whether HF was at baseline again. Since $>20 \mathrm{~min}$ is far longer than necessary to reach baseline of HF rate after a workload well within aerobic range (Hollmann and Hettinger 2000), no carry-over effect was expected, and therefore, we did not randomize the order the four settings, which were as follows:

- "classic" (1995) method with CC only (80 bpm)

- "classic" method, CC and AV (15:2, 80 bpm)

- actual method (2010), CC only (100 bpm)

- actual method, CC and AV (30:2, $100 \mathrm{bpm})$

Statistical evaluation was performed with SPSS software version 15 (paired Wilcoxon rank test for dependent data and Mann-Whitney $U$ test for independent data). $P<0.05$ was defined as significant. Since the workload measured during CPR was strictly within the aerobic endurance capacity, which means within the linear correlations of pulse rate, workload, and oxygen uptake, respectively, HF measured during steady state conditions while performing CPR was linear interpolated to the data of HF during ergometry.

The minimal requirements by a healthy person to perform resuscitation are influenced directly by the underlying philosophy of safety. Assuming the data are distributed according to Gauss' distribution, the limits of the probability can be calculated with the formulas given in any standard handbook about statistics (Harms 1976). If a probability of $80 \%$ is demanded that a given group will be able to provide sufficient workload, the minimum requirements are mean value $+0.85 \times$ standard variation $\left(s_{x}\right)$ (Harms 1976). For $85 \%$, this would be $+1.06 \times s_{x}$, for $90 \%+1.29 \times \mathrm{s}_{\mathrm{x}}$, and for $95 \%+1.65 \times \mathrm{s}_{\mathrm{x}}$. Based on these considerations, the minimal requirements derived carefully from study 1 are listed in Table 2 . If a person must be able to provide sufficient workload for 


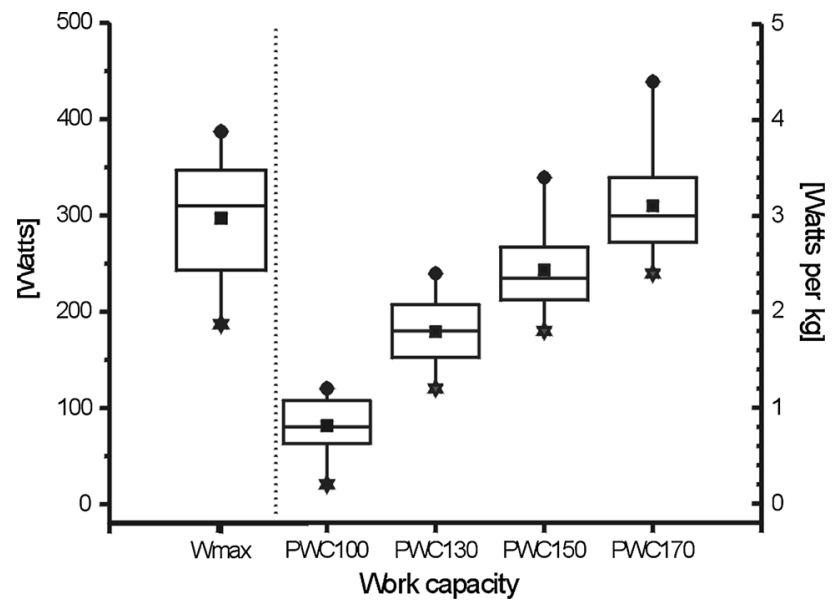

Fig. 1 Training status of the participants, expressed as maximum work capacity $\left(W_{\max }\right)$ in Watts and pulse work capacity (PWC, the work per $\mathrm{kg}$ body weight at the given pulse rate of $100,130,150$, or $170 /$ min) in Watts per $\mathrm{kg}$ body weight (study part 1 ). Normal values for the general population (adults) of Central Europe are the following: PWC130: 1.5/1.25 (males/females), PWC150: 2.0/1.6, PWC170: 2.5/2.0 (Hollmann and Hettinger 2000). Boxplot symbols: mean (small square), first and third quartiles (rectangle), median (horizontal line in rectangle), and extreme vales

resuscitation with a probability of $90 \%$, he should have a performance of $\sim 100 \mathrm{~W}$ or $\sim 2.2 \mathrm{~W} / \mathrm{kg}$, respectively, in bicycle ergometry at steady state conditions (Hollmann and Hettinger 2000).

With the condition to test healthy adult persons only, the study was fully accepted by the Ethical Commission of the University of Düsseldorf (No. 950).

\section{Results}

Anthropometric data of the participants in both studies were age $31.1 \mathrm{y}$ ( \pm 9.6 ; median 26 ; range $19-49)$ and body mass index $23.1 \mathrm{~kg} / \mathrm{m}^{2}( \pm 3.0$; median 22.6 ; range 19.6-32.2) for study one and 24.5 y $( \pm 2.4$; median 24 ; range $22-30)$ and $21.5 \mathrm{~kg} / \mathrm{m}^{2}( \pm 1.7$; median 21.9 ; range 18.3-24.2) for study 2 , respectively. There was no significant difference between both collectives for age or BMI. All probands completed the tests without any problems. Spiroergometric results are summarized in Fig. 1 and Table 1. All investigations followed reference values for normal ergometry. The data showed linear correlations with very high coefficients (HF vs. work load 0.983-0.995; $\mathrm{VO}_{2}$ vs. work load 0.968-0.987; $\mathrm{VO}_{2}$ vs. HF 0.981-0.994).

In study 1, the subjects' HF increased during CPR from $83.0 \mathrm{bpm}( \pm 11.3)$ to $109.9 \mathrm{bpm}( \pm 12.6 ; P=0.0004)$. This increase of $+32.4 \%$ corresponds to $58.3 \%$ of the expected maximum HF (220-years of age) and to $61.1 \%$ of the measured maximal HF. The ventilation per minute
Table 1 Results of spiroergometry and lactate kinetics of the participants (study 1)

\begin{tabular}{|c|c|c|c|}
\hline \multirow[t]{2}{*}{ Parameters } & \multirow[t]{2}{*}{ Unit } & \multicolumn{2}{|l|}{ Data } \\
\hline & & Mean & $\mathrm{Sx}^{\mathrm{h}}$ \\
\hline Pulse (at rest) & bpm & 76.9 & 9.2 \\
\hline Heart frequency (maximum) & bpm & 182.3 & 12.5 \\
\hline$W_{\max }^{\mathrm{a}}$ & $\mathrm{W}$ & 297 & 58.6 \\
\hline PWC $100^{b}$ & $\mathrm{~W} / \mathrm{kg}$ & 0.8 & 0.3 \\
\hline PWC $130^{\mathrm{b}}$ & $\mathrm{W} / \mathrm{kg}$ & 1.8 & 0.3 \\
\hline PWC $150^{\mathrm{b}}$ & $\mathrm{W} / \mathrm{kg}$ & 2.4 & 0.4 \\
\hline PWC $170^{\mathrm{b}}$ & $\mathrm{W} / \mathrm{kg}$ & 3.1 & 0.5 \\
\hline Lactate (at rest) & $\mathrm{mmol} / \mathrm{l}$ & 1.3 & 0.74 \\
\hline $\begin{array}{l}\text { Lactate (maximum, } 1 \text { min. after } \\
\text { ergometry) }\end{array}$ & $\mathrm{mmol} / \mathrm{l}$ & 9.2 & 2.37 \\
\hline Anaerobic threshold (Mader) & $\mathrm{W}$ & 169.6 & 36.3 \\
\hline $\begin{array}{l}\text { Anaerobic threshold } \\
\text { (Mader) per kg body weight }\end{array}$ & $\mathrm{W} / \mathrm{kg}$ & 2.4 & 0.57 \\
\hline $\mathrm{VO}_{2 \max }^{\mathrm{c}}$ & $\mathrm{ml} / \mathrm{min}$ & 3502 & 744 \\
\hline $\mathrm{VO}_{2 \max } / \mathrm{kg}^{\mathrm{d}}$ & $\mathrm{ml} / \mathrm{min} / \mathrm{kg}$ & 49.8 & 14.6 \\
\hline Ventilation per minute (at rest) & $1 / \min$ & 14.7 & 3.9 \\
\hline $\begin{array}{l}\text { Ventilation per minute } \\
\text { (at maximum load) }\end{array}$ & $1 / \min$ & 128.4 & 27.0 \\
\hline $\begin{array}{l}\text { Breathing frequency } \\
\text { (at maximum load) }\end{array}$ & $/ \min$ & 48.1 & 6.4 \\
\hline $\mathrm{VO}_{2 \max } / \mathrm{HF}^{\mathrm{e}}$ & $\begin{array}{c}\mathrm{ml} / \mathrm{min} / \\
\mathrm{bpm}\end{array}$ & 21.1 & 3.6 \\
\hline $\mathrm{SaO}_{2}(\text { at rest })^{\mathrm{f}}$ & $\%$ & 96.2 & 0.2 \\
\hline $\mathrm{SaO}_{2}(\text { at maximum load })^{\mathrm{f}}$ & $\%$ & 94.3 & 0.1 \\
\hline Arterial $\mathrm{pO}_{2}(\text { at rest })^{\mathrm{g}}$ & $\mathrm{mmHg}$ & 82.7 & 2.1 \\
\hline Arterial $\mathrm{pO}_{2}$ (at maximum load) ${ }^{\mathrm{g}}$ & $\mathrm{mmHg}$ & 78.8 & 2.2 \\
\hline
\end{tabular}

${ }^{\text {a }} W_{\max }$ maximal workload

b Pulse work capacity at a pulse rate of $100,130,150$, or $170 / \mathrm{min}$

c Maximal oxygen uptake

d Maximal oxygen uptake per kilogram body weight

e Maximal oxygen uptake per heartbeat

${ }^{\mathrm{f}}$ Oxygen saturation

g Oxygen partial pressure

${ }^{\text {h }}$ Standard deviation

increased from $14.7 \mathrm{l} / \mathrm{min}( \pm 3.9)$ at rest to $27.0 \mathrm{l} / \mathrm{min}$ $( \pm 6.3 ; P=0.0050)$ or for $+22.9 \%$, which corresponds to $47.3 \%$ of the maximum values measured in spiroergometry. Oxygen uptake $\left(\mathrm{VO}_{2}\right)$ at rest was $0.50 \mathrm{l} / \mathrm{min}( \pm 0.13)$ and showed an increase of $+126 \%$ during CPR (1.13 l/ $\min \pm 0.25 ; P=0.0004)$. This corresponds to $40.5 \%$ of the expected and to $32.2 \%$ of the measured maximum values. Relative $\mathrm{VO}_{2}$ was $6.9 \mathrm{ml} / \mathrm{min} / \mathrm{kg}( \pm 1.4)$ at rest and $15.6 \mathrm{ml} / \mathrm{min} / \mathrm{kg}( \pm 2.7 ; P=0.0004)$ during resuscitation. This is an increase of $+126 \%$, and maximum values correspond to $36.1 \%$ of those during spiroergometry. Oxygen consumption per heart beat $\left(\mathrm{VO}_{2} / \mathrm{HF}\right)$ showed a 
Table 2 Minimal requirements for people at risk to perform resuscitation without posing themselves at risk (top) and minimal requirements for a healthy population to perform resuscitation for different levels of safety (below, for details see text)

\begin{tabular}{llc}
\hline Parameters & Unit & Minimal requirements \\
\hline Workload & W/kg & $1.6-1.8$ \\
$\mathrm{HF}^{\mathrm{a}}$ & $/ \mathrm{min}$ & 110 \\
$\mathrm{Minute}^{\mathrm{a}}$ ventilation & $1 / \mathrm{min}$ & 27 \\
$\mathrm{VO}_{2}^{\mathrm{b}}$ & $1 / \mathrm{min}$ & 1.13 \\
\hline
\end{tabular}

Safety level

Workload in ergometry

(W) (W/kg)

Minimal requirements for a probability of $80 \%$

Minimal requirements for a probability of $85 \%$

Minimal requirements for a probability of $90 \%$

93.0

100.2

1.4

111.5
1.6

1.8

\footnotetext{
${ }^{a}$ Heart frequency

b Oxygen uptake
}

comparable increase: $6.6 \mathrm{ml} / \mathrm{bpm}( \pm 2.3)$ at rest and $10.0 \mathrm{ml} / \mathrm{bpm}( \pm 2.3)$ during CPR $(+51.5 \%$; $P=0.0044)$. This corresponds to $67.5 \%$ of the expected and $47.3 \%$ of the measured maximum values. Respiratory equivalent $\left(\mathrm{VE} / \mathrm{VO}_{2}\right)$ was $28.5( \pm 4.3)$ at rest and only $24.5( \pm 2.5)$ at work $(P=0.0113)$. Oxygen saturation $\left(\mathrm{SaO}_{2}\right)$ differed not between rest and work $(96.3 \% \pm 0.8$ vs. $96.0 \% \pm 3.6$; n.s.), the same for oxygen partial pressure $\left(\mathrm{pO}_{2}\right)$ with $82.2 \mathrm{mmHg}( \pm 8.7)$ at rest and $89.1 \mathrm{mmHg}( \pm 12.0)$ during CPR (n.s.). The workload in spiroergometry, which corresponds to those during CPR, is summarized in Table 2. Average workload during CPR is $64.3 \mathrm{~W}$ or $1.0 \mathrm{~W} / \mathrm{kg}$ body weight, respectively.

In part 2 of the study, the participants showed a relative high $\mathrm{HF}$ at rest of $90.8 \mathrm{bpm}( \pm 9.4)$, which may have been stress induced as all subjects watched as each performed CPR protocols, but this does not influence HF at workload (Hollmann and Hettinger 2000). The HF for the four different CPR situations as described above is shown in Fig 2. As expected, all situations i.-iv. showed significantly higher $\mathrm{HF}$ during $\mathrm{CPR}$ than at rest $(P<0.0001)$, but as in part 1 of the study, all HF during the activity were well within the range of aerobic endurance. The difference between the situations i. (CC: 80/min) and iii. (CC: $100 / \mathrm{min}$ ) is statistically significant $(P<0.05)$ as an effect of the increased workload by higher frequency of CC. Situations i. (CC $80 / \mathrm{min}$ ) and ii. $($ CC $80 / \mathrm{min}+\mathrm{AV})$ also differ significantly $(P<0.02)$. Obviously AV by the same person marginally increases the workload compared to CC only, but this increase of about $3 \mathrm{bpm}$ is clinically irrelevant as it is for the difference between situations iii. (CC: 100/min) and iv. (CC $100 /$ min + AV) with 2 bpm (n.s.). Interestingly, there is

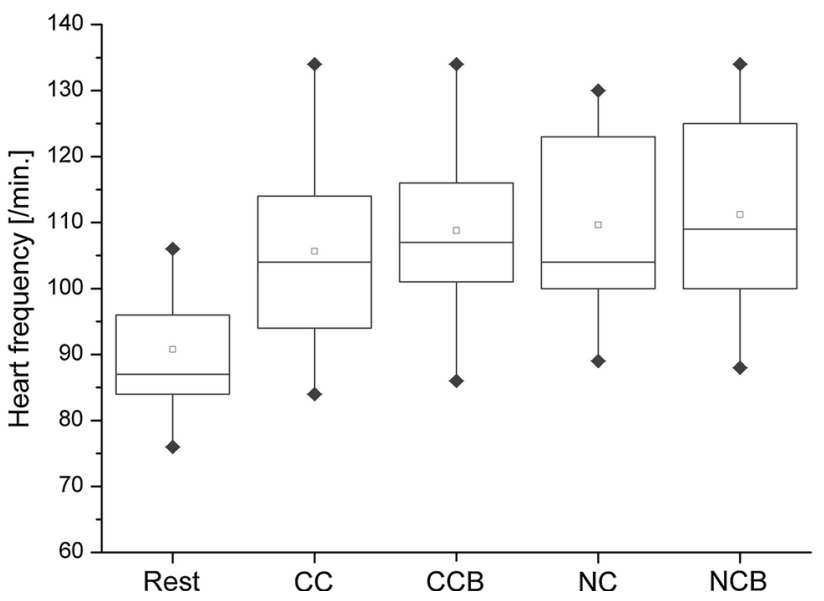

Fig. 2 Pulse rates in part 2. Rest: baseline (pulse rate at rest); CC: "classic" method, cardiac massage only (situation i.); CCB: "classic" method, cardiac massage, and artificial breathing (situation ii.); $N C$ new (actual) method, cardiac massage only (situation iii.), $N C B$ new (actual) method, cardiac massage, and artificial breathing (situation iv.)

no significant difference between situations ii. and iv. where the rescuer has to perform both $\mathrm{CC}$ and $\mathrm{AV}$, but at iv. with the higher frequency of $100 / \mathrm{min}$. It must be pointed out that the increase of the frequency of $\mathrm{CC}$ from $80 \mathrm{bpm}$ (situation i.) to $100 \mathrm{bpm}$ (situation iii.), which is a surplus of $+20 \%$, does not result in an increase of the rescuer's $\mathrm{HF}$ for $+20 \%$ but for $+\sim 3 \%$ only. The respective data of the combination of $\mathrm{CC}$ and $\mathrm{AV}$ (situation ii. and iv.) is $+2 \%$. All rescuers performed CPR with correct technique (insufficient frequency or depth of CPR was recorded in 4-6\% of the CC for all measurements of both parts of the study). 


\section{Discussion}

CPR is a well-established standard procedure practiced, globally for cardiac emergencies. Considering the increasing age of Western populations that are statistically significant at an increasing risk of cardiac arrest, it is increasingly likely that such persons may seek lay CPR training or be involved in the resuscitation of victims. It is therefore possible that a rescuer with preexisting CPD may be putting both their life and that of the victim at risk when performing CPR. Fortunately medical complications during CPR training are rare events (N.N. 1983) (Sullivan and Avstreih 2000), although it is not clear whether this is because they are really rare or because only a few persons with preexisting diseases join.

There is a linearity between HF and workload or oxygen uptake, respectively, until the aerobic-anaerobic threshold is reached (Hollmann and Hettinger 2000; McGehee et al. 2005) (Conconi et al. 1982). At sea level, this at about 140 bpm (Hollmann and Hettinger 2000) or below a blood lactate concentration of $4 \mathrm{mmol} / \mathrm{l}$ (Mader and Heck 1986). One might criticize that $3 \mathrm{~min}$ of exercise is too short to evaluate workload during CPR because a real CPR situation lasts much longer. However, Hollmann et al. showed that in several papers over decades that after three minutes of a respective constant aerobic workload, a plateau phase is reached which is quite stable (Hollmann and Hettinger 2000). For such a workload, there will be no change of data when longer measurements should be performed. Our data of study part 1 prove that CPR can be performed within the aerobic range. Therefore, the plateau phase gives sufficient data for the rest of the activity. Of course, if CPR would be an activity which is beyond the anaerobic threshold, another approach would be necessary.

The HF of all participants of part 1 was well within this linear range mentioned above. Therefore, it was possible to reduce data acquisition in part 2 on $\mathrm{HF}$ alone. However, this comparison may not reflect the ergonomics of muscular work done during CPR, which uses the muscles of the upper, rather than lower body. However, as bicycle ergometry is widely used, and steady states of exercise can be easily prescribed, we choose this for standard investigations to check whether a person may be able to perform resuscitation. As a routine procedure and outcome of such a testing, which should be limited to classifying workload rather than investigating complex physiological systems, the difference of the results caused by unequal ergonomics may be neglected. With workload $[$ Watts $]=9.81 \times$ body weight $[\mathrm{kg}] \times$ speed $[\mathrm{m} / \mathrm{s}] \times \sin$ $\alpha(\sin \alpha=$ inclination of the treadmill), our results can be transformed if treadmill ergometry should be performed (de Marées and Mester 1981) (Hollmann and Hettinger 2000).
Our data are within the range of those given by Betz et al. who reported an increase of HF from $102 \mathrm{bpm}$ to $106 \mathrm{bpm}$, which is, like ours, statistically significant, but clinically irrelevant (Betz et al. 2008). Like us, they investigated healthy people only, so a direct deduction of recommendations for cardiac patients is as limited as in our actual study. Others also investigated the workload of CPR, again only in healthy persons (Bridgewater et al. 2008). For the old 15:2 rhythm, they reported $76 \%( \pm 2)$ of the maximum $\mathrm{HF}$ and $79 \%( \pm 2)$ for the $30: 2$ rhythm. The rate pressure product did not differ significantly. Comparing their results with ours, both findings indicate a slight but not a critical increase of the rescuer's workload when following the 2010 recommendations.

There is another significant bias perhaps in both studies: It is impossible to blind the study design, and all participants expected a higher workload with an increase in metronome beats. To quantify such a self-assessment, the so-called Borg's scale, a semiquantitative scale that provides valid data to weight workload, has been widely used (Borg and Noble 1974; Borg 2004). But the use has some limitations, e.g., the increase of two classes in Borg's scale as reported by Bridgewater is definitively more than the difference in the workload of both CPR procedures. Several anecdotal complaints of medicine personnel would seem to indicate that $100 / \mathrm{min}$ CCs are substantially more tiring than $80 / \mathrm{min}$. This is a consequence of human's ability to quantify workload quite good especially within the range of a HF between $\sim 80$ and $140 \mathrm{~min}^{-1}$, but this may also interfere with expectations and other psychic factors. The effect causes the subjective impression of a significantly increased workload, although all data prove that even the higher frequency of $\mathrm{CC}$ is performed far below the anaerobic threshold. A similar effect was found in an early study about workload during CPR (Pierce et al. 1992).

Our results and the derived minimal requirements are within the range of the data given by Shultz et al.(Shultz et al. 1995). But it must be pointed out that this prediction is exclusively true for healthy persons and at low altitude. With workload provided above, these limits healthy persons with a moderate training level will be able to perform CPR within the range of aerobic endurance, hence for the period of $30 \mathrm{~min}$ according to the recommendations for CPR by lay persons. The workload of CPR corresponds to the mean endurance capacity of a healthy untrained Western population (Aigner 1985; Shephard et al. 1988; Jenny et al. 1998). But as a consequence of several factors, maximum workload decreases with age (Hollmann and Hettinger 2000; Hollmann et al. 1981, 1992). However, Liesen and Hollmann reported a PWC150 of $95 \mathrm{~W}$ in untrained women and $160 \mathrm{~W}$ in untrained men at the age of 70 (Hollmann and Hettinger 2000; Liesen and Hollmann 
1981). This is clearly sufficient to fulfill the minimal criteria of our study. For untrained males, Liesen reported a decrease from $32 \mathrm{ml} / \mathrm{kg} / \mathrm{min}$ at the age of 55-59 years to $30 \mathrm{ml} / \mathrm{kg} / \mathrm{min}$ at $60-65$ years and $28 \mathrm{ml} / \mathrm{kg} / \mathrm{min}$ in the 66-70 years group (Liesen et al. 1975). For trained men, the corresponding values were 34,33 , and $33 \mathrm{ml} / \mathrm{kg} / \mathrm{min}$. These values would provide much more potential workload than necessary for CPR where we measured $15.6 \mathrm{ml} / \mathrm{kg} /$ $\min$. This would be in accordance with others who reported no effect of age on perceived exertion during CPR training (Bridgewater et al. 2000). The absolute peak HF of the older participants (51-65 years) was $116 / \mathrm{min}$, which is within the same range than our collective. The problem may be more pronounced if patients should perform CPR, but patients with hemodialysis were able to provide $1.1 \mathrm{~W} /$ $\mathrm{kg}$ before and $1.4 \mathrm{~W} / \mathrm{kg}$ after erythropoietin treatment (Wizemann et al. 1992). This would enable them to perform CPR according to our data.

When CPR training should be performed at high-altitude locations, a decrease of aerobic performance $\left(\mathrm{VO}_{2} \max \right)$ of about $11.5 \%$ per $1000 \mathrm{~m}$ of altitude beyond $1500 \mathrm{~m}$ above sea level must be taken into account for healthy persons (Buskirk et al. 1967; Hansen et al. 1967; Dill et al. 1966). This decrease is independent from training status and gender (Rupwate et al. 1990). For persons with CPD, the situation is more complex. A minor decrease of performance has been found at moderate altitude $(600-1,500 \mathrm{~m}$ (Fulco et al. 1998; Terrados et al. 1985). Others found an increase in cardiac output for the same workload during the early phase of altitude exposure (=non-acclimatized persons) (West 1990; Vogel et al. 1967). Vogel et al. reported an increase of cardiac output of $12 \%$ at rest and of 16-18\% for all levels of workload during ergometry and of $+20 \%$ for the recovery phase (Vogel et al. 1967). There are no data available concerning people with CPD performing CPR or such trainings at altitude. On the other hand, such patients rarely go to altitude locations above $3000 \mathrm{~m}$. However, they should be trained very carefully, especially during the acclimatization phase. A survey concerning performance and risks of CPD patients has been reviewed by the Medical Commission of the Union Internationale des Associations d'Alpinisme (Donegani et al. 2012, 2014).

In case of cardiac risk, a limit of the workload at $75-80 \%$ of the ischemic or symptomatic threshold is generally accepted (Hollmann and Hettinger 2000). In consequence, the limits given above must be increased appropriately. A pulmonary patient without a significant limitation of gas diffusion should be able to breathe about $30 \mathrm{l} / \mathrm{min}$. In case of limited gas exchange, a $\mathrm{VO}_{2}$ of $1.13 \mathrm{l} /$ min is essential. All CPD patients should take care to perform CPR without forced respiration during expulsion because this would considerably increase their blood pressure.
The study has some limitations. An extrapolation from a group of persons without CPD to people with such risks must be interpreted carefully. But with several congruent results, a pulse rate well below the anaerobic threshold, and with the pulse rate commonly used for safety management in sports of cardiac patients, our careful interpretation of the minimal requirements should be acceptable. A future CPR study should test our data with patients who suffer from coronary heart disease or significant pulmonary disease to confirm our extrapolation. Of course, a typical collective at risk of cardiac diseases is older than those investigated here. But since $\mathrm{VO}_{2}$ for a given workload is independent from age and gender, this should not cause significant errors (Hollmann and Hettinger 2000). Of course, the maximum HF of older persons is lower and therefore they will reach their individual limits earlier.

Bicycle ergometry may cause a bias of the data as the legs get a workload, not the muscles of the upper body used during CPR. It is well known that arm ergometry would cause a significantly higher increase in pulse rate and blood pressure for a given workload. But with correct technique, there is not much workload on the arm muscles. CPR should be performed with straight arms and the weight of the upper body as the load used to apply the pressure to the patient's thorax. When done correctly, CPR does not really load the arms, but the muscles of the trunk when the rescuer reduces the pressure between each CC. The effect on circulatory parameters of such a work was never investigated.

A third limitation is difficult to quantify: the effect of stress on HF during a real resuscitation. This will vary a lot, since knowledge, training status, experience, personal stress management, and many other factors will interfere. Some of them may increase this effect, while others like experience will reduce it. There are no data available which quantify these effects during real resuscitation.

The testing period was limited to $3 \mathrm{~min}$, although most resuscitations last much longer. But since the data of all tests clearly show that CPR is performed strictly within the range of aerobic endurance, this does not cause a bias (Hollmann and Hettinger 2000).

A well-known problem is the variability of the resistance of the thorax of different persons and the necessity to find a realistic average to construct a manikin. This also includes the dynamic forces, but detailed data about such forces in the human's thorax are not available. Individual and environmental factors also influence the resistance: The large thorax of a huge person has a higher resistance than those of a small thin person, and a patient with severe hypothermia shows significantly increased resistance. Tomlinson et al. investigated the forces during CPR in 91 adult patients and reported a mean force of $30.3 \pm 8.2 \mathrm{~kg}$ (Tomlinson et al. 2007). Strictly spoken, they have used the 
wrong measurement unit (kg scales masses while $\mathrm{N}$ scales forces), but however, there were two important conclusions: (1) an average-sized rescuer should be able to perform effective CPR in most adult patients although there was a decrease of applied forces of $1.5 \mathrm{~kg}$ for each 10 -year increase in age, and (2) the mean absolute compression depth was $42 \pm 8 \mathrm{~mm}$. The latter indicates that the new recommendations that include a depth of at least $50 \mathrm{~mm}$ may be not realistic. In summary, it is impossible to obtain detailed data for any person or situation by investigations with manikins, but since the manufacturers take care to optimize the devices to cover as much persons or situations as possible, the manikins represent the "average adult Caucasian". Therefore, our results should include a minor bias only if such a "standard person" is discussed. In such situations, it is a general consensus to include safety margins in the specific recommendations to avoid dangerous situations. Since the safety reduction mentioned above is well established in international recommendations for safe sport of heart patients, it should also be safe in resuscitation.

In order to comply with ethical permission for testing, our studies were performed with young adults. Since there is a decrease of aerobic endurance capacity with age (Hollmann et al. 1981; Hollmann and Hettinger 2000) and others have shown that the force applied during CPR decreases with age (Tomlinson et al. 2007), it may be questionable whether a significant portion of people of $70+$ years of age will be able to provide the workload given above. A future study should therefore also include elderly volunteers.

We cannot calculate exactly the workload of the myocardium since we did not measure blood pressure during CPR. In contrast to ergometry, it is impossible to get reliable data about blood pressure during CPR by the RivaRocci method. Since blood pressure decreases immediately when any workload is stopped, the Riva-Rocci method would cause significant bias. The problem could be solved by arterial measurement which may be considered in future studies.

Recently the recommendations for CPR have been changed again. Now the frequency of $\mathrm{CC}$ should be $100-120 / \mathrm{min}$ and the depth of each compression should be 5-6 cm (European Resuscitation Council) or $5 \mathrm{~cm}$ (AHA). This may slightly increase the workload on the rescuer, but since these recommendations were published after our study was performed, we cannot give details about that.

Finally, there is an ethical question: Should a person who knows that he or she is at risk because of a preexisting disease perform resuscitation or not? This also includes the training at manikins. There is no doubt that even severe preexisting diseases do not prevent anybody from initializing the rescue chain, the alarm call. Our data indicate that heart patients at NYHA stage I (N.N. 1994) should not at risk of cardiac problem when performing CPR, while those at stages III and IV will be unable to do so. The problem group are patients at NYHA stage II. Most of them should be able to perform CPR within their individual limitations of safety, but the several factors may interfere and require individual safety precautions if such patients join CPR training. We suggest that such training be performed under the supervision of a physician only. This does not prevent cardiac symptoms or incidences, but it decreases the risk of such incidences. The patients should use a pulse watch which measures continuously and with the alarm set at $70-80 \%$ of the individual's ischemic rsp. symptomatic threshold. This procedure is well established for aerobic endurance sports with heart patients since 50 years and well supported by data. It was proved that the method may be used independently from the individual's diagnosis if the maximal acceptable pulse rate is defined as (70-) $80 \%$, where any problem which may be linked to the diagnosis occurs (survey in Hollmann and Hettinger 2000). Of course, this needs an optimized diagnosis of the ischemic or symptomatic threshold. Here some apparent international differences should be taken into account: While a workload of $85 \%$ of the age predicted heart rate is recommended for standard exercise tests in some countries, which is a submaximal test which reduces the likelihood of precipitation of a coronary event to $<1: 1,000$, in the German-speaking countries, higher workload is used. Here maximal HF, the onset of symptoms or significant ECG alterations are defined as limiting factors (=maximal test). A meta-analysis of 150 studies has shown that this results in a predictive value of $91 \%$ with a specificity of $77 \%$ and a variation coefficient of $\sim 10 \%$ (Lollgen 2005). The positive prediction of ischemic heart disease is $68 \%$ with the first stress test and increases to $>90 \%$ with repeated testing (Rost and Hollmann 1982a). It should be noted that "significant ECG alterations" differ: while in Central Europe this is any ST decrease of more than $0.1 \mathrm{mV}$, it is $0.4 \mathrm{mV}$ in some American centers. This and several other differences are of significant influence on the prediction of cardiac risk as well on the patient's safety during testing or workload (Rost and Hollmann 1982b). The patient's safety may be increased even more by stress echocardiography: since the onset of alterations of the myocardial relaxation or contraction is earlier than ECG alterations, this may be used to define the individual threshold (Nixdorff et al. 1997). However, if an individual has cardiac disease particularly cardiac ischemia or history of heart failure and develops symptoms at workloads similar to those identified in this mannequin study, then caution should be advised. Any patient whose cardiopulmonary or circulatory disease is not in stabilized condition should not join CPR trainings until the disease is under control. 
We would also recommend that standard equipment for ALS is available to optimize the physician's work if an incident should occur. Whether a heart patient performs CPR in a real situation is purely a personal decision. If he is afraid of engaging in a higher workload by performing $\mathrm{CC}$ combined with $\mathrm{AV}$, the rescuer may also choose to only perform CC. Recent data have shown that AV is obviously less important than previously assumed and that the final outcome is not reduced when lay rescuers exclude AV and only perform a sufficient CC (Bobrow et al. 2010.). However, our data indicate that CPR with CC only does not reduce workload significantly compared to $\mathrm{CC}+\mathrm{AV}$. Therefore, the reduction of a full CPR to CC only should be more a mental than a physical reduction of workload. This also indicates that such a strategy would not reduce the risk for persons with preexisting risk factors.

As our data indicate, there is no simple mathematical correlation between the frequency of $\mathrm{CC}$ and the rescuer's HF: $+20 \%$ of compressions ( 80 bpm vs. $100 \mathrm{bpm}$ ) induced an increase in the rescuer's HF for only $3 \%$. In consequence, any patient, who is anxious to overburden himself when performing or training CPR, cannot reduce significantly his or hers workload by following the older recommendations with lower frequency of CC. In consequence, any rescuerwith preexisting disease or not-should follow the actual guidelines when he or she should join a CPR training or if they should face a real resuscitation.

Acknowledgments The investigation was part of the research project "Demands on Rescuers at Alpine Accidents." The project was granted by the Austrian Society for Alpine and Altitude Medicine (ÖGAHM). Many thanks to Cosmed Germany, Siemens and Marquette-Hellige Medical Systems Germany, who supported the study with loaned equipment. The authors wish to thank all participants for their voluntarily and enthusiastic commitment to the project.

Conflict of interest None.

\section{References}

Aigner A (1985) Sportmedizin in der Praxis. Verlag Brüder Hollinek, Wien

Betz AE, Callaway CW, Hostler D, Rittenberger JC (2008) Work of CPR during two different compression to ventilation ratios with real-time feedback. Resuscitation 79(2):278-282

Bobrow BJ, Spaite DW, Berg RA, Stolz U, Sanders AB, Kern KB, Vadeboncoeur TF, Clark LL, Gallagher JV, Stapczynski JS, LoVecchio F, Mullins TJ, Humble WO, Ewy GA (2010) Chest compression-only CPR by lay rescuers and survival from out-ofhospital cardiac arrest. JAMA 304(13):1447-1454

Borg G (2004) Anstrengungsempfinden und körperliche Aktivität. Dt Ärztebl 101(15):B840-845

Borg G, Noble BJ (1974) Perceived exertion. In: Wilmore JH (ed) Exercise and sport sciences review, vol 2. Academic Press, London, pp 131-153

Bridgewater FH, Bridgewater KJ, Zeitz CJ (2000) Using the ability to perform CPR as a standard of fitness: a consideration of the influence of aging on the physiological responses of a select group of first aiders performing cardiopulmonary resuscitation. Resuscitation 45(2):97-103

Bridgewater FH, Zeitz C, Field J, Inglis A, Poulish K (2008) The impact of the ILCOR 2005 CPR guidelines on a physical fitness assessment: a comparison of old and new protocols. Resuscitation 76(3):405-412

Buskirk ER, Kollias J, Akers RF, Prokop EK, Reateagui EP (1967) Maximal performance at altitude and on return from altitude in conditioned runners. J Appl Physiol Respir Environ Exerc Physiol 23:259-267

Castagna C, Chaouachi A, Rampinini E, Chamari K, Impellizzeri F (2009) Aerobic and explosive power performance of elite Italian regional-level basketball players. J Strength Cond Res 23(7):1982-1987

Church TS, Earnest CP, Morss GM (2002) Field testing of physiological responses associated with Nordic Walking. Res Q Exerc Sport 73(3):296-300

Conconi F, Ferrari M, Ziglio PG, Droghetti P, Codeca L (1982) Determination of the anaerobic threshold by a noninvasive field test in runners. J Appl Physiol Respir Environ Exerc Physiol 52(4):869-873

de Marées H, Mester J (1981) Sportphysiologie I. Diesterweg, Frankfurt

Dill DB, Myhre G, Phillips EE Jr, Brown DK (1966) Work capacity in acute exposures to altitude. J Appl Physiol Respir Environ Exerc Physiol 21(4):1168-1176

Donegani E, Hillebrandt D, Windsor J, Küpper T, Gieseler U, Rodway GW (2012) Consensus statement of the UIAA Medical Commission Vol.21: People with Pre-existing Cardiovascular Conditions Going to the Mountains. Union International des Associations d'Alpinisme, Medical Commission. www.theuiaa. org/medical_advice.html. Accessed 6.5.2014

Donegani E, Hillebrandt D, Windsor J, Gieseler U, Rodway GW, Schöffl V, Küpper T (2014) People with Pre-existing Cardiovascular Conditions Going to the Mountains. Travel Med Inf Dis (TMAID):(in press)

Fulco CS, Rock PB, Cymerman A (1998) Maximal and submaximal exercise performance at altitude. Aviat Space Environ Med 69(8):793-801

Handley AJ, Becker LB, Allen M, Drenth A, Kramer E, Montgomery MH, Chandra NC, Dick WF, Idris A (1997) Einfache lebensrettende Sofortmassnahmen beim Erwachsenen. Eine Rahmenempfehlung des International Liaison Committee on Resuscitation (ILCOR). Notfallmed 23:208-215

Hansen JE, Vogel JA, Stelter GP, Consolazio CF (1967) Oxygen uptake in man during exhaustive work at sea level and high altitude. J Appl Physiol Respir Environ Exerc Physiol 23(4):511-522

Harms V (1976) Tabellenanhang (Tabelle II). In: Harms V (ed) Biomathematik, Statistik und Dokumentation. 2. Aufl. edn. Harms Verlag, Kiel, p 179

Hollmann W, Hettinger T (2000) Sportmedizin, Grundlagen für Arbeit. Training und Präventivmedizin. Schattauer, Stuttgart

Hollmann W, Liesen H, Rost R, Heck H (1981) The behavior of the physical performance capacity and the trainability of the cardiopulmonary system in elder persons (author's transl). Aktuelle Gerontologie 11(3):91-95

Hollmann W, Rost R, Mader A, Liesen H (1992) Altern. Leistungsfähigkeit und Training. Dt Ärztebl 89(38):B1930-B1937

Jenny E, Schaffert W, Lämmle T, Burtscher M (1998) Sportärztlich-, höhenmedizinische-, sportwissenschaftliches Tabellarium für den Bergsteiger. In: Jenny E, Riedmann G, Flora G, Berghold F (eds) Jahrbuch 1998 der Österreichischen Gesellschaft für Alpin- und Höhenmedizin. Österreichische Gesellschaft für Alpin- und Höhenmedizin, Innsbruck, pp 185-210 
Johnston TC, Clark MJ, Dingle GA, FitzGerald G (2003) Factors influencing Queenslanders' willingness to perform bystander cardiopulmonary resuscitation. Resuscitation 56(1):67-75

Kelly KJ (1986) Teaching and credentialing the physically challenged: state of the art. A review of change in the clinical and scientific data since 1980. Circulation 74 (6 Pt 2):IV66-69

Kida M, Kawamura T, Fukuoka T, Tamakoshi A, Wakai K, Ohno Y, Toyama J (2004) Out-of-hospital cardiac arrest and survival: an epidemiological analysis of emergency service reports in a large city in Japan. Circ J 68(7):603-609

Klinger M (2009) Quantification of the cardiorespiratory endurance by a submaximal step test. University of Vienna/Austria, Wien

Lejeune PO, Delooz HH (1987) Why did persons invited to train in cardiopulmonary resuscitation not do so? Eur Heart J 8(3):224-228

Liesen H, Hollmann W (1981) Ausdauersport und Stoffwechsel. Hofmann, Schondorf

Liesen H, Heikkinen E, Suominen H, Michel D (1975) Der Effekt eines 12-wöchigen Ausdauertrainings auf die Leistungsfähigkeit und den Muskelstoffwechsel bei untrainierten Männern des 6 . und 7. lebensjahrzehnts. Sportarzt Sportmed 2:26

Lollgen H (2005) Auswertung des Belastungs-EKG [Evaluation of ECGs in stress tests]. In: Lollgen $\mathrm{H}$ (ed) Kardiopulmonale Funktionsdiagnostik [Cardiopulmonary diagnostics]. 4th ed. edn. Novartis Pharma GmbH, Nuremberg/Germany, pp 271-279

Lonergan JH, Youngberg JZ, Kaplan JA (1981) Cardiopulmonary resuscitation: physical stress on the rescuer. Crit Care Med 9(11):793-795

Mader A, Heck H (1986) A theory of the metabolic origin of "anaerobic threshold". Int J Sports Med 7(Suppl 1):45-65

Mader A, Liesen H, Heck H, Philippi H, Rost R, Schürch P, Hollmann W (1976) Zur Beurteilung der sportartspezifischen Ausdauerleistungsfähigkeit im Labor (Teil 2). Sportarzt Sportmed 5:109-112

McGehee JC, Tanner CJ, Houmard JA (2005) A comparison of methods for estimating the lactate threshold. J Strength Cond Res 19(3):553-558

Neumann G (1993) Bicycle sports. In: Shephard RJ, Astrand P-O (eds) Endurance in sports. Deutscher Ärzteverlag, Köln, pp 560-571

Neumar RW, Otto CW, Link MS, Kronick SL, Shuster M, Callaway CW, Kudenchuk PJ, Ornato JP, McNally B, Silvers SM, Passman RS, White RD, Hess EP, Tang W, Davis D, Sinz E, Morrison LJ (2010) Part 8: adult advanced cardiovascular life support: 2010 American Heart Association Guidelines for Cardiopulmonary Resuscitation and Emergency Cardiovascular Care. Circulation 122(18 Suppl 3):S729-767

Nixdorff U, Mohr-Kahaly S, Wagner S, Meyer J (1997) Klinischer Stellenwert der Stress-Echokardiographie [Clinical value of stress echocardiography]. Dt Ärztebl 94 (A1723)

N.N. (1983) CPR: a report of observed medical complications during training. Ann Emerg Med 12(3):194-195

N.N. (1994) The Criteria Committee of the New York Heart Association. Nomenclature and Criteria for Diagnosis of Diseases of the Heart and Great Vessels. In: N.N. (ed) The Criteria Committee of the New York Heart Association. Nomenclature and Criteria for Diagnosis of Diseases of the Heart and Great Vessels. 9th ed. edn. Little, Brown \& Co, Boston, Mass, pp 253-256

N.N. (2000) Guidelines 2000 for Cardiopulmonary Resuscitation and Emergency Cardiovascular Care. Part 3: adult basic life support.
The American Heart Association in collaboration with the International Liaison Committee on Resuscitation. Circulation 102 (8 Suppl):I22-59

N.N. (2010) Demographischer Wandel in Deutschland, Heft 2: Auswirkungen auf Krankenhausbehandlungen und Pflegebedürftige im Bund und in den Ländern. Wiesbaden

Nolan JP, Deakin CD, Soar J, Bottiger BW, Smith G (2005) European Resuscitation Council guidelines for resuscitation 2005. Section 4. Adult advanced life support. Resuscitation 67(Suppl 1):S39-86

Pierce EF, Eastman NW, McGowan RW, Legnola ML (1992) Metabolic demands and perceived exertion during cardiopulmonary resuscitation. Percept Mot Skills 74(1):323-328

Rost R, Hollmann W (1982a) Belastungs-EKG [Stress ECG]. In: Rost R, Hollmann W (eds) Belastungsuntersuchungen in der Praxis [Practicising stress tests]. Thieme, Stuttgart, pp 101-121

Rost R, Hollmann W (1982b) Risiko der Belastungsuntersuchung [Risk of stress tests]. In: Rost R, Hollmann W (eds) Belastungsuntersuchungen in der Praxis [Practicising stress tests]. Thieme, Stuttgart, pp 69-74

Rupwate RU, Chitaley M, Kamat SR (1990) Cardiopulmonary functional changes in acute acclimatisation to high altitude in mountaineers. Eur J Epidemiol 6(3):266-272

Shephard RJ, Bouhlel E, Vandewalle H, Monod H (1988) Peak oxygen intake and hypoxia: influence of physical fitness. Int $\mathrm{J}$ Sports Med 9(4):279-283

Shultz JJ, Mianulli MJ, Gisch TM, Coffeen PR, Haidet GC, Lurie KG (1995) Comparison of exertion required to perform standard and active compression-decompression cardiopulmonary resuscitation. Resuscitation 29(1):23-31

Spitzer H, Hettinger T, Kaminski G (1982) Tafeln für den Energieumsatz bei körperlicher Arbeit. Beuth Verlag, Berlin

Stiell I, Nichol G, Wells G, De Maio V, Nesbitt L, Blackburn J, Spaite D (2003) Health-related quality of life is better for cardiac arrest survivors who received citizen cardiopulmonary resuscitation. Circulation 108(16): 1939-1944

Sullivan F, Avstreih D (2000) Pneumothorax during CPR training: case report and review of the CPR literature. Prehosp Disaster Med 15(1):64-69

Terrados N, Mizuno M, Andersen H (1985) Reduction in maximal oxygen uptake at low altitudes; role of training status and lung function. Clin Physiol 5(Suppl 3):75-79

Tomlinson AE, Nysaether J, Kramer-Johansen J, Steen PA, Dorph E (2007) Compression force-depth relationship during out-ofhospital cardiopulmonary resuscitation. Resuscitation 72(3):364-370

Tucker KJ, Larson JL, Idris A, Curtis AB (1995) Advanced cardiac life support: update on recent guidelines and a look at the future. Clin Cardiol 18(9):497-504

Vogel JA, Hansen JE, Harris CW (1967) Cardiovascular responses in man during exhaustive work at sea level and high altitude. J Appl Physiol Respir Environ Exerc Physiol 23(4):531-539

Vogt PA (2004) Effect of an 1.5 year endurance training on the lipoprotein profile and oxygenation of low density lipoproteins. Eberhard-Karls-Universität, Tübingen

West JB (1990) Tolerance to severe hypoxia: lessons from Mt. Everest. Acta Anaesthesiol Scand Suppl 94:18-23

Wizemann V, Kaufmann J, Kramer W (1992) Effect of erythropoietin on ischemia tolerance in anaemic hemodialysis patients with confirmed coronary artery disease. Nephron 62(2):161-165 